\title{
Alcohol, Liver Function Tests, and High Density Lipoprotein Cholesterol in University Students
}

\author{
Shozo Nakamura \\ Tohoku University Health Center, Sendai 980
}

\begin{abstract}
Nakamura, S. Alcohol, Liver Function Tests, and High Density Lipoprotein Cholesterol in University Students. Tohoku J. exp. Med., 1980, 132 (2), 241-242 - Among non-obese students, those consuming daily $44 \mathrm{~g}$ or more of alcohol showed significantly higher incidences of abnormality in glutamic oxalacetic transaminase (GOT) and $\gamma$-glutamyl transpeptidase ( $\gamma$-GTP). When daily alcoholic intake of $44 \mathrm{~g}$ or more was combined with obesity, highly significant increase in incidences of abnormality in GOT, glutamic pyruvic transaminase (GPT), and $\gamma$-GTP was observed. In normal weight students, even lower range of alcoholic consumption was associated with significant increase in high density lipoprotein (HDL) cholesterol. As compared with normal weight groups, obesity groups showed significantly lower HDL cholesterol, and leanness group significantly higher HDL cholesterol. alcohol; liver function tests; high density lipoprotein cholesterol; university student; obesity
\end{abstract}

Recently relationship between alcoholic intake and high density lipoprotein (HDL) cholesterol was noted (Castelli et al. 1977; Williams et al, 1979). Hitherto, however, studies were not done in young people. Therefore, alcoholic intake was investigated in university students, and were correlated with liver function tests and HDL cholesterol.

5935 male university students were asked about daily alcoholic intake. After being divided into groups according to alcoholic intake, blood was sampled at random from a part of the students of each group. Glutamic oxalacetic transaminase (GOT), glutamic pyruvic transaminase (GPT), $\gamma$-glutamyl transpeptidase ( $\gamma$-GTP), and HDL cholesterol were determined by convetional methods in a total of 229 students, and were correlated with alcoholic intake and body weight. When obesity or leanness groups were compared, those consisting of less than 8 students were excluded. Matsumoto's modified table of Metropolitan Life Insurance Company was used for the standard body weight. GOT, GPT, and $\gamma$-GTP were thought to be abnormal when values exceeded means plus 3 times standard deviations (i.e., 29 Karmen Units for GOT, 25 Karmen Units for GPT, and $30 \mathrm{mU} / \mathrm{ml}$ for $\gamma$-GTP) of non-obese students consuming daily 0-3 $\mathrm{g}$ of alcohol. HDL cholesterol was measured both by the precipitation method (Burnstein et al. 1970) and by the electrophoresis method (Cobb and Sanders 1978).

Daily alcoholic consumption in the male university students averaged $8.4 \mathrm{~g}$, and $2.5 \%$ of the students consumed daily $44 \mathrm{~g}$ or more of alcohol.

Among non-obese students, those consuming daily $44 \mathrm{~g}$ or more of alcohol showed significantly higher incidences of abnormality in GOT and in $\gamma$-GTP, though the extent of the increase was slight $(p=0.02$, Table 1$)$. When daily alcoholic intake of $44 \mathrm{~g}$ or more was combined with obesity, highly significant increase in incidences of abnormality in GOT, GPT, and $\gamma$ GTP was observed $(p<0.001, p=0.003, p<0.001)$. Thus the influence of alcoholic intake on GOT and $\gamma-$ GTP was shown in university students in spite of their short history of drinking, and combined effect of alcohol and obesity on the liver was evident.

Received for publication, April 30, 1980. 
TABLE 1. Incidences of abnormal GOT, GPT, and $\gamma-G T P$ in relation to alcoholic consumption and obesity

\begin{tabular}{cccccc}
$\begin{array}{c}\text { Alcohol } \\
\text { (g/day) }\end{array}$ & $\begin{array}{c}\text { Relative } \\
\text { weight }\end{array}$ & $\begin{array}{c}\text { Number of } \\
\text { students }\end{array}$ & GOT & GPT & $\gamma-$ GTP \\
\hline $0-3$ & $<110$ & 75 & $0 \%$ & $1 \%$ & $1 \%$ \\
$4-21$ & $<110$ & 71 & $1 \%$ & $3 \%$ & $1 \%$ \\
$22-43$ & $<110$ & 36 & $3 \%$ & $3 \%$ & $3 \%$ \\
$44-$ & $<110$ & 29 & $10 \%^{*}$ & $10 \%$ & $14 \%^{*}$ \\
\hline $0-3$ & $>110$ & 9 & $0 \%$ & $0 \%$ & $0 \%$ \\
$44-$ & $>110$ & 9 & $44 \%^{+}$ & $33 \% \dagger$ & $44 \%_{+}^{+}$ \\
\hline
\end{tabular}

The difference from non-obese students with daily alcoholic intake of $0-3 \mathrm{~g}: * p=0.02$, $\dagger p=0.003, \ddagger p<0.001$.

TABLE 2. Mean HDL cholesterol in relation to alcoholic consumption and body weight

\begin{tabular}{ccccc}
$\begin{array}{c}\text { Alcohol } \\
\text { (g/day) }\end{array}$ & $\begin{array}{c}\text { Relative } \\
\text { weight }\end{array}$ & $\begin{array}{c}\text { Number of } \\
\text { students }\end{array}$ & $\begin{array}{c}\text { Precipitation } \\
\text { method }(\mathbf{m g} / \mathbf{l 0 0} \mathbf{m l})\end{array}$ & $\begin{array}{c}\text { Electrophoresis } \\
\text { method (\%) }\end{array}$ \\
\hline 0 & $90-110$ & 16 & 43.8 & 31.5 \\
$1-3$ & $90-110$ & 40 & $50.8^{*}$ & 34.0 \\
$4-21$ & $90-110$ & 57 & $52.1 \dagger$ & 34.7 \\
$22-43$ & $90-110$ & 33 & $53.1^{*}$ & 33.5 \\
$44-$ & $90-110$ & 24 & $56.6 \dagger$ & $38.9 \dagger$ \\
\hline $1-3$ & $<90$ & 12 & 49.3 & 34.6 \\
$4-21$ & $<90$ & 16 & $61.4 \$$ & 41.38 \\
$1-3$ & $>110$ & 8 & $42.6 \ddagger$ & $27.1 \ddagger$ \\
$44-$ & $>110$ & 9 & 54.6 & $31.8 \ddagger$ \\
\hline
\end{tabular}

The difference from teetotalers: $* p<0.02, \uparrow p<0.01$.

The difference from the normal weight group: $\ddagger p<0.05, \S p<0.01$.

In normal weight students, even lower range of alcoholic consumption was associated with significant increase in mean $\mathrm{HDL}$ cholesterol measured by the precipitation method (Table 2). Students consuming daily $44 \mathrm{~g}$ or more of alcohol revealed significant increase in both HDL cholesterol measured by the precipitation method $(p<0.01)$ and that by the electrophoresis method $(p<0.01)$. As compared with normal weight groups, both obesity groups showed significantly lower HDL cholesterol, and one of the 2 leanness groups significantly higher HDL cholesterol (Table 2). Thus the relationship of HDL cholesterol to alcoholic intake and body weight was confirmed in university students.

\section{References}

1) Burnstein, M., Scholnick, H.R. \& Morfin, R. (1970) Rapid method for the isolation of lipoprotein from human serum by precipitation with polyanions. J. Lipid Res., 11, 583-595.

2) Castelli, W.P., Doyle, J.T., Gordon, T., Hames, C.G., Hjortland, M.C., Hulley, S.B., Kagan, A. \& Zukel, W.J. (1977) Alcohol and blood lipids; The cooperative lipoprotein phenotyping study. Lancet, 2, 153-155.

3) Cobb, S.A. \& Sanders, J.L. (1978) Enzymic determination of cholesterol in serum lipoproteins separated by electrophoresis. Clin. Chem., 24, 1116-1120.

4) Matsumoto, S. (1972) Criteria of obesity. Nippon Ishikai Zasshi (J. Jap. med. A.ss.), 68, 916-919. (Japanese)

5) Williams, P., Robinson, D. \& Bailey, A. (1979) High-density lipoprotein and coronary risk factors in normal men. Lancet, 1, 72-75. 